\title{
Simultaneous Bilateral Spontaneous Pneumothorax: Report of 6 Adult Patients
}

\author{
Ahmed I. Al-Azzawi \\ Department of Cardiothoracic and Vascular Surgery, Faculty of Medical Sciences, School of Medicine, \\ University of Sulaimaniyah, Sulaimaniyah, Iraq \\ Email: alazzawi69@yahoo.com
}

Received 13 January 2015; accepted 31 January 2015; published 3 February 2015

Copyright (C) 2015 by author and Scientific Research Publishing Inc.

This work is licensed under the Creative Commons Attribution International License (CC BY). http://creativecommons.org/licenses/by/4.0/

(c) (1) 0pen Access

\begin{abstract}
Background: Spontaneous pneumothorax (SP) refers to the spontaneous presence of air in the pleural sac(s) without iatrogenic or traumatic factors. The simultaneous bilateral SP (SBSP) is rare yet serious clinical condition which may pose a significant threat to patient's life. Herein, 6 patients with SBSP managed in Sulaimaniyah Teaching Hospital (STH) over 6-year period (20062011) are reported with literature review. Methodology: A prospective clinical study. The diagnosis was made on clinical and radiographic grounds. The initial therapy was a bilateral tube thoracostomy (BTT) followed by chemical pleurodesis. Thoracotomy for excision of subpleural blebs or bullae and pleurectomy was performed for prolonged air leak (lasting >14 days). Results: There were 5 males $(83.33 \%)$ and 1 female $(16.67 \%)$ with a mean age of 34.8 years ranging between 20 and 50. All patients had presented with dyspnea and chest pain and were smokers. Three patients (50\%) had primary (PSP) whereas the remaining had secondary (SSP) (chronic obstructive pulmonary disease-COPD, $n=2$ and pneumonia, $n=1$ ). None of the patients had recurrence. Unilateral thoracotomy was necessary in 5 patients (SSP, $n=3$ and PSP, $n=2)$. Prolonged air leak was observed once postoperatively $(16.7 \%)$ while mortality was nil. Conclusions: Prompt recognition of this rare yet potentially serious condition is crucial. The clinical diagnosis is straightforward with plain chest radiography being the most helpful workup. The initial therapy is via BTT followed by pleurodesis. Surgery is necessary for prolonged air leak and failure of the lung to expand.
\end{abstract}

\section{Keywords}

Primary, Secondary, Simultaneous Bilateral Spontaneous Pneumothorax, Pleurodesis

\section{Introduction}

Spontaneous pneumothorax refers to the spontaneous presence of air in the pleural sac(s) without iatrogenic or 
traumatic factors. The primary form mostly affects young healthy males with a special body built (slim and tall) having normal lungs apart from subpleural apical blebs whose rupture is generally considered the causative mechanism. In contrast, the secondary form may occur in elderly people with underlying pulmonary lesions such as COPD. The SBSP is rare yet serious clinical condition which may pose a significant threat to patient's life [1]. Acute presentation of SP may be life-threatening. The need for vigilance and early recognition is crucial [1].

In the US, the incidence of PSP is 7.4/100,000 in men and 1.2/100,000 in women whereas the incidence of SSP is 6.3/100,000 in men and 2/100,000 in women [2]. Simultaneous BSP is a rare condition and forms only 1.3\% of all spontaneous pneumothorax cases [3] [4]. Unlike unilateral SP, patients with SBSP have usually underlying lung disease [5] [6]. The overall male to female ratio of SP is 5:1 [7]. The higher incidence in men has been attributed to higher rates of smoking, body habits, and different mechanical properties of the lung [7]. Simultaneous BSP can be fatal once it progresses into tension pneumothorax [8] [9]. Simultaneous BSP is mainly seen in patients with chronic obstructive pulmonary disease, tuberculosis, pneumonia, undefined interstitial pulmonary disease, connective tissue disease, and pulmonary metastasis [10]. Herein, 6 patients with SBSP managed in STH (the main surgical hospital in the city) over 6-year period (2006-2011) are reported with literature review.

\section{Material and Methods}

Informed written consent was taken from all patients to be enrolled in this prospective clinical study. The diagnosis was made on clinical grounds (careful history and physical examination) (Figure 1) together with plain chest radiograms in all cases (Figure 2 and Figure 3). Computerized tomography (CT) scan of the chest was performed for cases with SSP to figure out underlying lung disease (Figure 4). Fiberoptic bronchoscopy (FOB) was performed in all patients to rule out any endobronchial lesion. The initial therapy was a bilateral tube

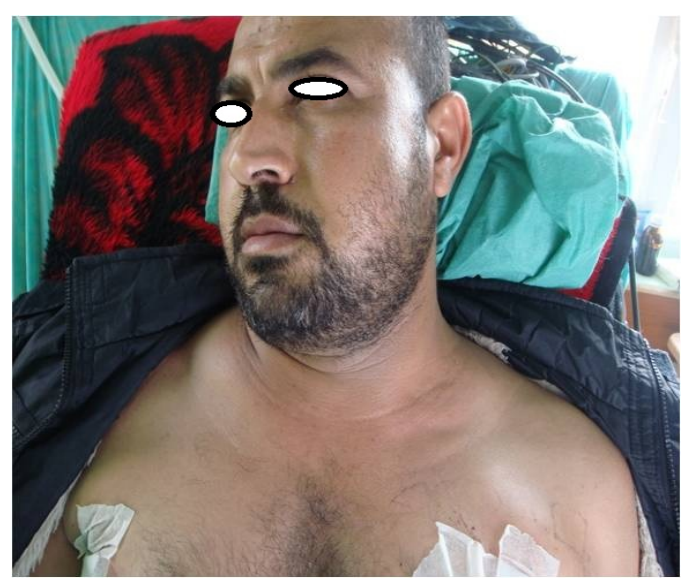

Figure 1. Surgical emphysema in a patient with SP.

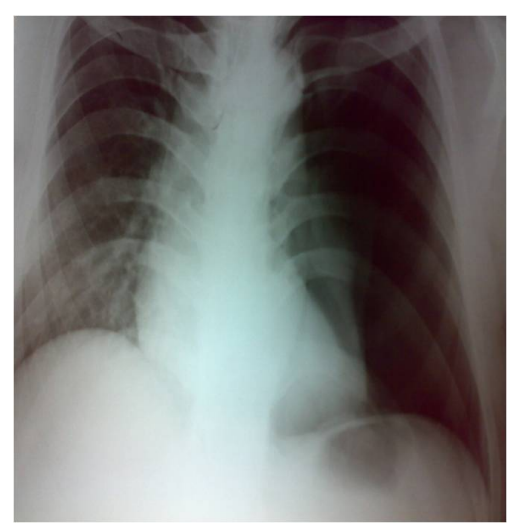

Figure 2. Left-side SP. 


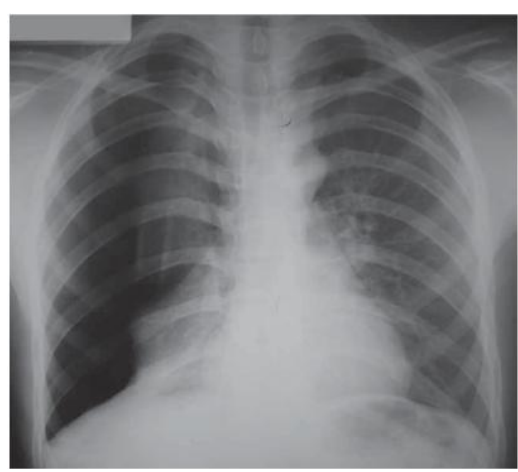

Figure 3. Bilateral spontaneous pneumothorax.

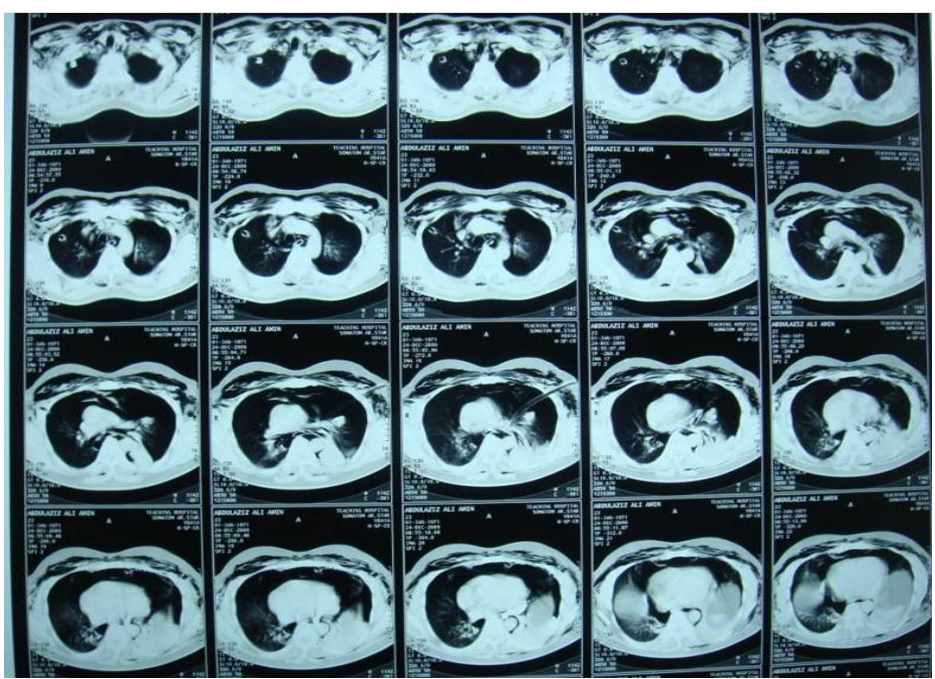

Figure 4. Computerized tomography scan of the chest for a patient with left-sided SP.

thoracostomy to relieve the symptoms and achieve lung expansion (Figure 5 and Figure 6). The chest tubes were removed when air leak stopped and the associated fluid drainage was less than $150 \mathrm{ml}$ in 24 hours and the lung was re-expanded. In order to prevent future recurrences, bilateral pleurodesis (with Tetracycline) was intended in all patients. Thoracotomy for excision of subpleural blebs or bullae and pleurectomy (Figure 7(a) and Figure 7(b)) was performed for prolonged air leak (lasting $>14$ days). Patients had a close observation in the postoperative period (Figure 8 and Figure 9) and a clinical-radiographic follow-up for 1 year to diagnose a recurrence of pneumothorax.

\section{Results}

Six patients ( 5 males and 1 female) were studied. The age ranged between 20 and 50 years with a mean of 34.8 . Symptoms were dyspnea and chest pain $(n=6)$, productive cough $(n=1)$, sweating $(n=1)$, weight loss and malaise $(n=1)$ and moderate subcutaneous emphysema $(n=1)$. All patients had history of smoking. Three patients (50\%) had PSP and three (50\%) had SSP (COPD, $\mathrm{n}=2$ and Staphylococcus aureus pneumonia, $\mathrm{n}=1$ ).

All patients had immediate BTT once the diagnosis was made which significantly improved the symptoms. Chemical pleurodesis (with Tetracycline) was then attempted few days later in all patients. The youngest patient in this series (a man of 20 with PSP) was managed by BTT and chemical pleurodesis without thoracotomy while unilateral thoracotomy was necessary in 5 patients (SSP, $n=3$ and PSP, $n=2$ ) due to prolonged air leak. During thoracotomy, blebs or bullae were seen and managed by blebectomy or bullectomy combined with localized pleurectomy opposite to the site of blebs or bullae to achieve pleurodesis and prevent future recurrence of 


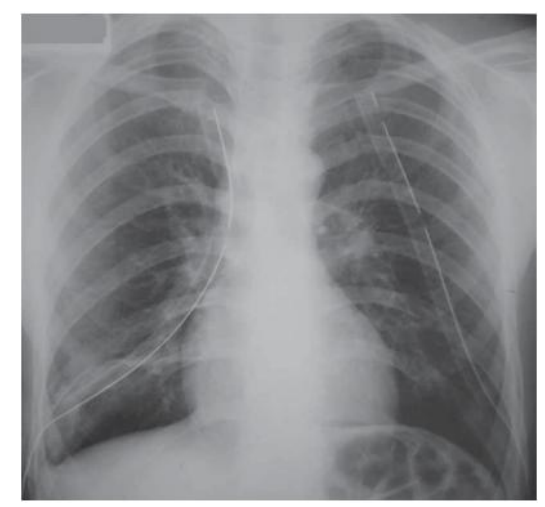

Figure 5. Fully expanded lungs following bilateral tube thoracostomies for BSP.

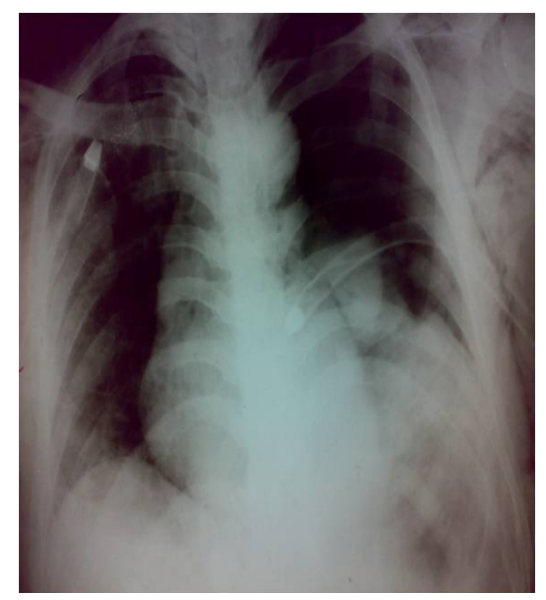

Figure 6. BSP with incomplete lung expansions.

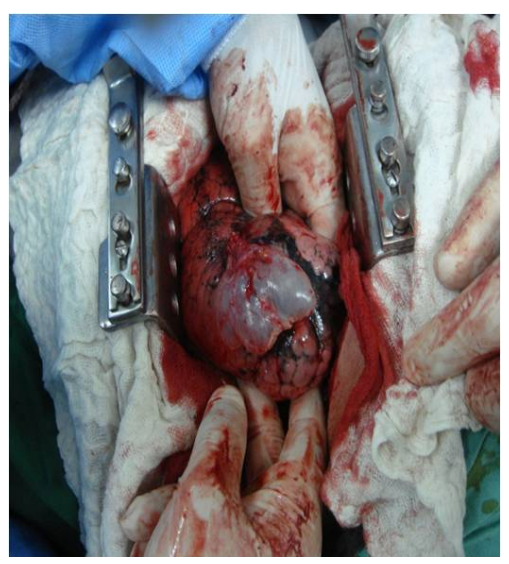

(a)

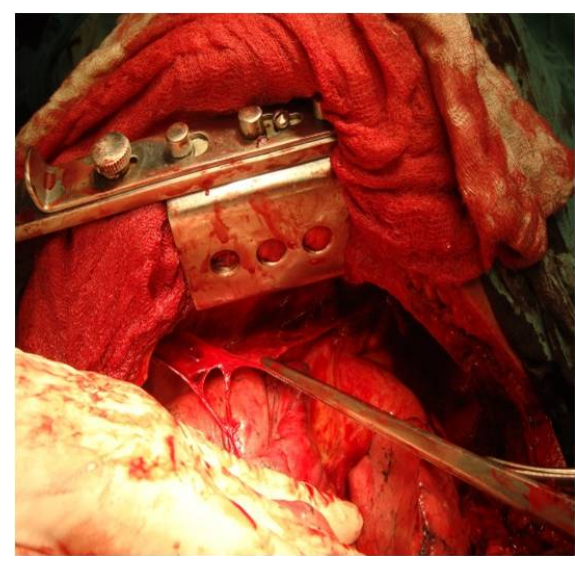

(b)

Figure 7. (a) Intra-operative photograph showing a big bullous; (b) Intra-operative photograph showing a localized pleurectomy.

pneumothorax. The postoperative complications included prolonged air leak $(n=1,16.67 \%)$ which stopped after 10 days and wound infection $(n=1,16.67 \%)$ managed conservatively. All patients were followed-up for at least 1 year. No recurrence and no mortality were recorded during this period. 


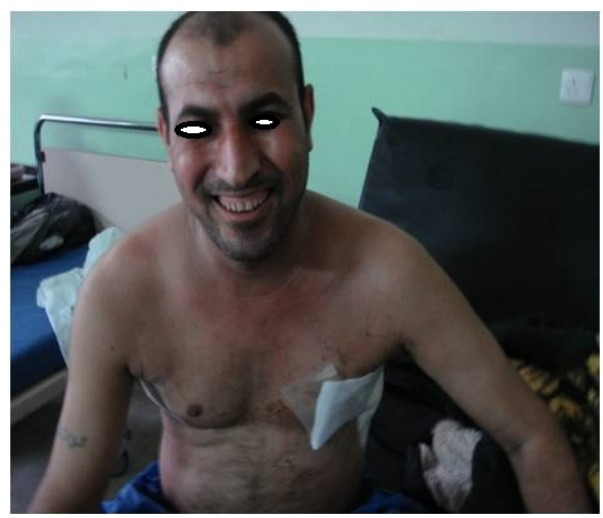

Figure 8. Postoperative photograph showing resolved surgical emphysema.

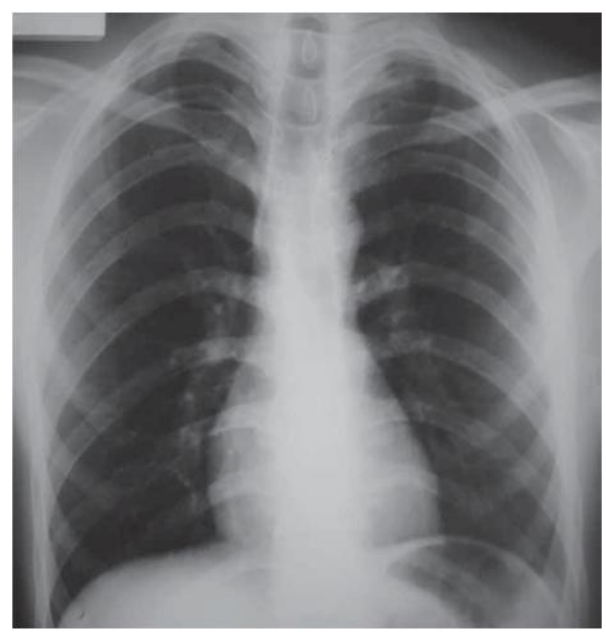

Figure 9. Postoperative chest radiograph at the time of hospital discharge.

\section{Discussion}

Although in clinical practice, SP is a frequently encountered disease, SBSP is rarely reported in the literatures [2]-[4]. However, it represents a significant health problem. It is generally ascribed to rupture of an intra-thoracic gas-containing structure. Air enters the pleural space when a subpleural apical bleb or a pulmonary cavity ruptures [8]. Most SBSP cases are seen as a result of an underlying pulmonary disease, such as chronic obstructive pulmonary disease, malignant neoplasm, or lung tuberculosis [10]. Infrequently, SBSP may be caused by the pleural window communicating with both pleural spaces [10]. In the literature, some SBSP cases have been reported in association with malignancies [11].

Between 1971 and 1990, Esther et al. [3] detected 12 cases of SBSP (PSP, $n=5$ and SSP, n = 7). Our cases were equally divided into primary and secondary SP but none was found in conjunction with malignancy.

Iraj et al. [12] found a significant association between bullae and SSP. Serious systemic diseases could be present in SBSP cases, and respiratory stress could be life threatening [13]. For this reason, patients should be carefully evaluated and receive clear diagnoses. It is generally accepted that rupture of apical subpleural emphysematous blebs causes PSP. It has been reported that SP is seen more frequently in smokers than in nonsmokers. Primary SP is most frequently seen in people aged 20 - 29, whereas SSP generally occurs in the elderly [9] [10]. Our patients with SSP were middle-aged.

Simultaneous BSP cases vary in clinical presentation. Patients may present alternating clinical signs and symptoms, ranging from mild dyspnea to cardiopulmonary failure [14]. Patients are usually admitted to the hospital with sudden onset of dyspnea and pleuritic chest pain on the side of the pneumothorax. Physical examina- 
tions can appear normal in minimal pneumothorax cases [7]-[9].

In patients with significant pneumothorax, hyper-resonance is detected with percussion, and breath sounds are diminished or lost. All of our patients had sudden onset of dyspnea and chest pain. Plain chest radiography forms the basis of the radiological examination. Computerized tomography of the thorax is indicated to detect underlying causes of spontaneous pneumothorax [11] [14]. Eventhough pneumothorax is a relatively easily suspected disease based on a patient's history and physical examination, a delay in hospital admission and radiological evaluation could threaten patient's life due to worsened state of ventilation and oxygenation. In bilateral pneumothorax cases, diminished breath sounds in both lungs should not mislead the physician, and SBSP should be considered.

The main aims of therapy of SP are to achieve complete lung expansion and prevent a recurrence. The treatment modalities include needle aspiration, percutaneous catheter drainage, tube thoracostomy with chemical pleurodesis, video-assisted thoracoscopic surgery (VATS) and thoracotomy. Hatta et al. immediately performed a bilateral tube thoracostomy on an 18-year-old SBSP patient. Afterward, they performed a thoracotomy via axillary incisions and reported excellent results [15]. Similarly, Ohara et al. [16] used the same procedure with an SBSP patient.

Neal et al. [17] reported performing a bilateral bleb resection by median sternotomy. Today, VATS is accepted as a standard approach for the surgical treatment of SP in most clinics. This surgical procedure enables the surgeon to fully evaluate the entire thoracic cavity by video. The existence of pleural communications could be investigated as well as inspection of the mediastinal pleura. Moreover, VATS causes less postoperative pain and yields smaller cosmetic scars [10].

Surgical treatment is recommended to reduce the risk of recurrence in SBSP [10] [11]. Bullectomy is the most effective method for preventing recurrences. In addition, apical pleurodesis further reduces the risk of recurrence.

Chest drainage constitutes the basis of initial treatment [11] [14] [18]. Air leakage can be stopped in 5 hours in $52 \%$ and in 48 hours in $82 \%$ of patients with tube thoracostomies [19]. Prolonged air leakage is the most common indication for operation in the first attack. Most clinicians advice surgical treatment in cases of prolonged air leakage that lasts more than 7 - 10 days. There are some studies indicating that air leakage absolutely needs to be stopped in 15 days, and the decision to operate would be made before the end of this period [20]. After relieving the patient's symptoms using a chest tube, a primary or secondary pneumothorax distinction can be made. Planning additional surgical procedures or pleurodesis according to the patient's clinical presentation and underlying disease is more appropriate [21].

\section{Conclusions}

Prompt recognition of this rare yet potentially serious condition is crucial. The clinical diagnosis is straightforward with plain chest radiography being the most helpful workup. The initial therapy is via BTT followed by pleurodesis. Surgery is necessary for prolonged air leak and failure of the lung to expand. When available, videoassisted thoracoscopic surgery is superior to open surgery for blebectomy or bullectomy and pleurectomy in SP patients.

\section{Acknowledgements}

I am immensely grateful to Prof. Abdulsalam Y. Taha, MBChB. FICMS (CTVS)/Department of Cardiothoracic and Vascular Surgery/School of Medicine/University of Sulaimaniyah for his tremendous efforts in reviewing and re-writing the manuscript.

\section{Conflict of Interest}

None declared.

\section{References}

[1] Light, R.W. (1994) Pneumothorax. In: Murray, J.F., Ed., Textbook of Respiratory Medicine, Vol. 2, WB Saunders, Philadelphia, 2193-2208

[2] Melton III, L.J., Helper, N.G.G. and Offord, K.P. (1979) Incidence of Spontaneous Pneumothorax in Olmsted County, 
Minnesota: 1950 to 1974. American Review of Respiratory Disease, 120, 1379-1381.

[3] Graf-Deuel, E. and Knoblauch, A. (1994) Simultaneous Bilateral Spontaneous Pneumothorax. Chest, 105, 1142-1146. http://dx.doi.org/10.1378/chest.105.4.1142

[4] Druepple, L.G. and Cox, W.A. (1974) Simultaneous Bilateral Spontaneous Pneumothorax. Military Medicine, 139, 296-299.

[5] Teixidor, S.J., Estrada, S.G., Sole, M.J., et al. (1994) Spontaneous Pneumothorax Apropos 2505 Cases. Archivos de Bronconeumología, 30, 131-135.

[6] Gupta, D., Mishra, S., Faruqi, S. and Aggarwal, A.N. (2006) Etiology and Clinical Profile of Spontaneous Pneumothorax in Adults. Indian Journal of Chest Disease and Allied Science, 48, 261-264.

[7] Athanassiadi, K., Kalavrouziotis, G., Loutsidis, A., et al. (1998) Treatment of Spontaneous Pneumothorax: Ten Year Experience. World Journal of Surgery, 22, 803-806. http://dx.doi.org/10.1007/s002689900473

[8] Graf-Deuel, E. and Knoblauch, A. (1994) Simultaneous Bilateral Spontaneous Pneumothorax. Chest, 105, $1142-1146$. http://dx.doi.org/10.1378/chest.105.4.1142

[9] Sayar, A., Turna, A., Metin, M., et al. (2004) Simultaneous Bilateral Spontaneous Pneumothorax Report of 12 Cases and Review of the Literature. Acta Chirurgica Belgica, 104, 572-576.

[10] Yamada, S., Yoshino, K. and Inoue, H. (2008) Simultaneous Bilateral Spontaneous Pneumothorax with Pleural Window Communicating with Bilateral Pleural Spaces. Annals of Thoracic Surgery, 85, 1434-1436. http://dx.doi.org/10.1016/j.athoracsur.2007.10.033

[11] Graf-Deuel, E. and Knoblauch, A. (1994) Simultaneous Bilateral Spontaneous Pneumothorax. Chest Journal, 105, 1142-1146. http://dx.doi.org/10.1378/chest.105.4.1142

[12] Mohebbi, I., Hassani, E., Salarilak, S. and Bahrami, A.R. (2007) Do Bullae and Emphysema Increase Risk of Pneumothorax in Silicosis? Journal of Occupational Medicine and Toxicology, 1, 8.

[13] Takahashi, S., Yokoyama, T., Ninomiya, N., Yokota, H. and Yamamoto, Y. (2006) A Case of Simultaneous Bilateral Spontaneous Pneumothorax Developed into Tension Pneumothorax. Journal of Nippon Medical School, 73, 29-32. http://dx.doi.org/10.1272/jnms.73.29

[14] Sayar, A., Turna, A., Metin, M., Kucukyagci, N., Solak, O. and Gurses, A. (2004) Simultaneous Bilateral Spontaneous Pneumothorax, Report of 12 Cases and Review of Literature. Acta Chirurgica Belgica, 104, 572-576.

[15] Hatta, T., Mastuda, S., Kuris, S., Ohyabu, H., Tachibana, S., Kita, Y., et al. (1993) A Case of Simultaneous Bilateral Pneumothorax. Kyobu Geka, 46, 287-289.

[16] Ohara, K., Yamazaki, T., Sakaguchi, K., Nakayama, M. and Kobayashi, A. (1994) A Case of Simultaneous Bilateral Spontaneous Pneumothorax. Kyobu Geka, 47, 1110-1111.

[17] Neal, J.F., Vargas, G., Smith, D.E., Akl, B.F. and Edwards, W.S. (1979) Bilateral Bleb Excision through Median Sternotomy. American Journal of Surgery, 138, 794-797. http://dx.doi.org/10.1016/0002-9610(79)90298-8

[18] Eroglu, A., Turkyilmaz, A., Aydin, Y., Erdem, A.F. and Çinici, Ö. (2007) Treatment of Secondary Spontaneous Pneumothorax: 100-Patient Experience. Eurasian Journal of Medicine, 39, 97-102.

[19] Baumann, M.H. and Strange, C. (1997) Treatment of Spontaneous Pneumothorax: A More Aggressive Approach? Chest Journal, 112, 789-804. http://dx.doi.org/10.1378/chest.112.3.789

[20] Chee, C.B., Abisheganaden, J., Yeo, J.K., Lee, P., Huan, P.Y.M., Poh, S.C. and Wang, Y.T. (1998) Persistent Air-Leak in Spontaneous Pneumothorax: Clinical Course and Outcome. Respiratory Medicine, 92, 757-761. http://dx.doi.org/10.1016/S0954-6111(98)90008-7

[21] Aydin, Y., Turkyilmaz, A., İntepe, Y.S. and Eroglu, A. (2010) Simultaneous Bilateral Spontaneous Pneumothorax: A Rare Emergency Clinical Condition. Eurasian Journal of Medicine, 42, 5-8. 
Scientific Research Publishing (SCIRP) is one of the largest Open Access journal publishers. It is currently publishing more than 200 open access, online, peer-reviewed journals covering a wide range of academic disciplines. SCIRP serves the worldwide academic communities and contributes to the progress and application of science with its publication.

Other selected journals from SCIRP are listed as below. Submit your manuscript to us via either submit@scirp.org or Online Submission Portal.
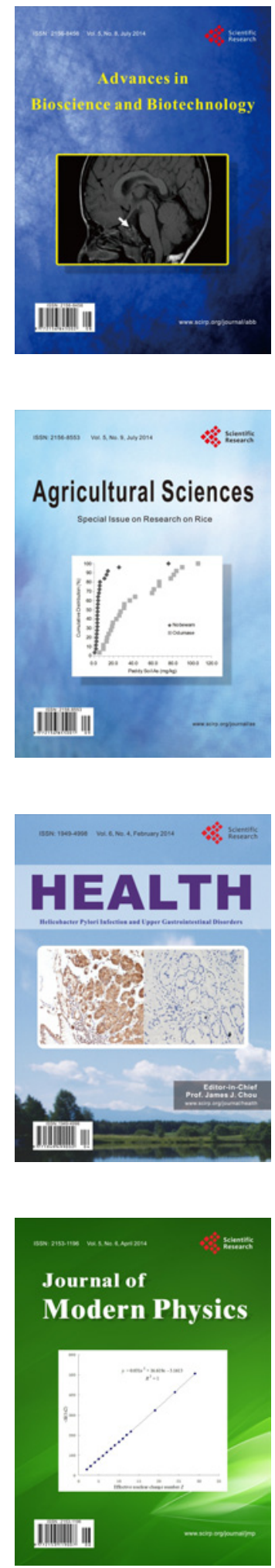
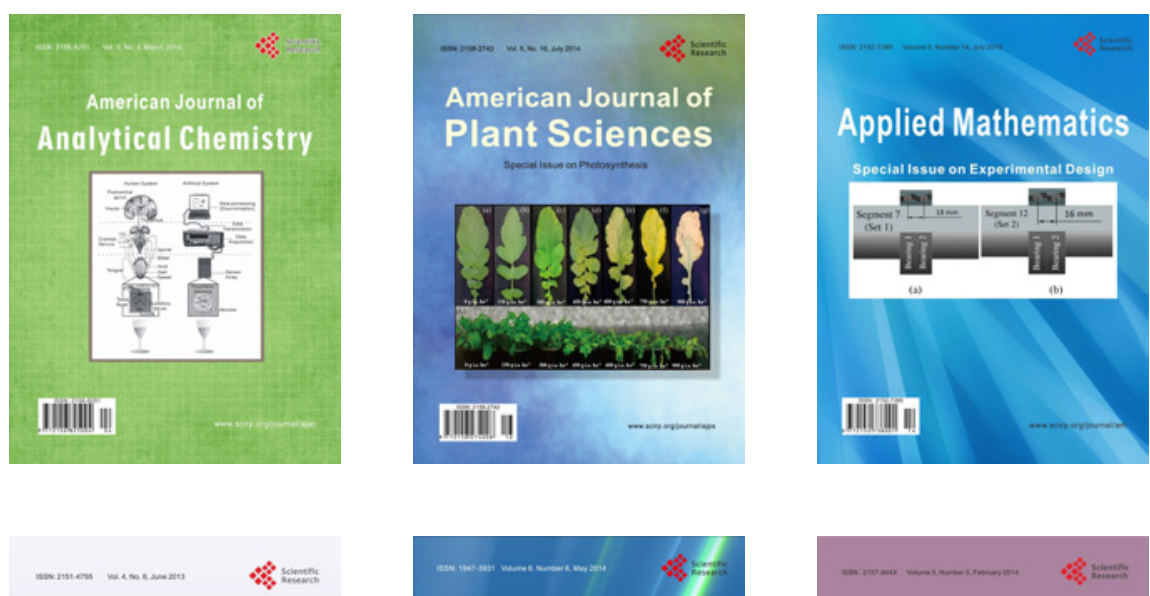

Creative Education
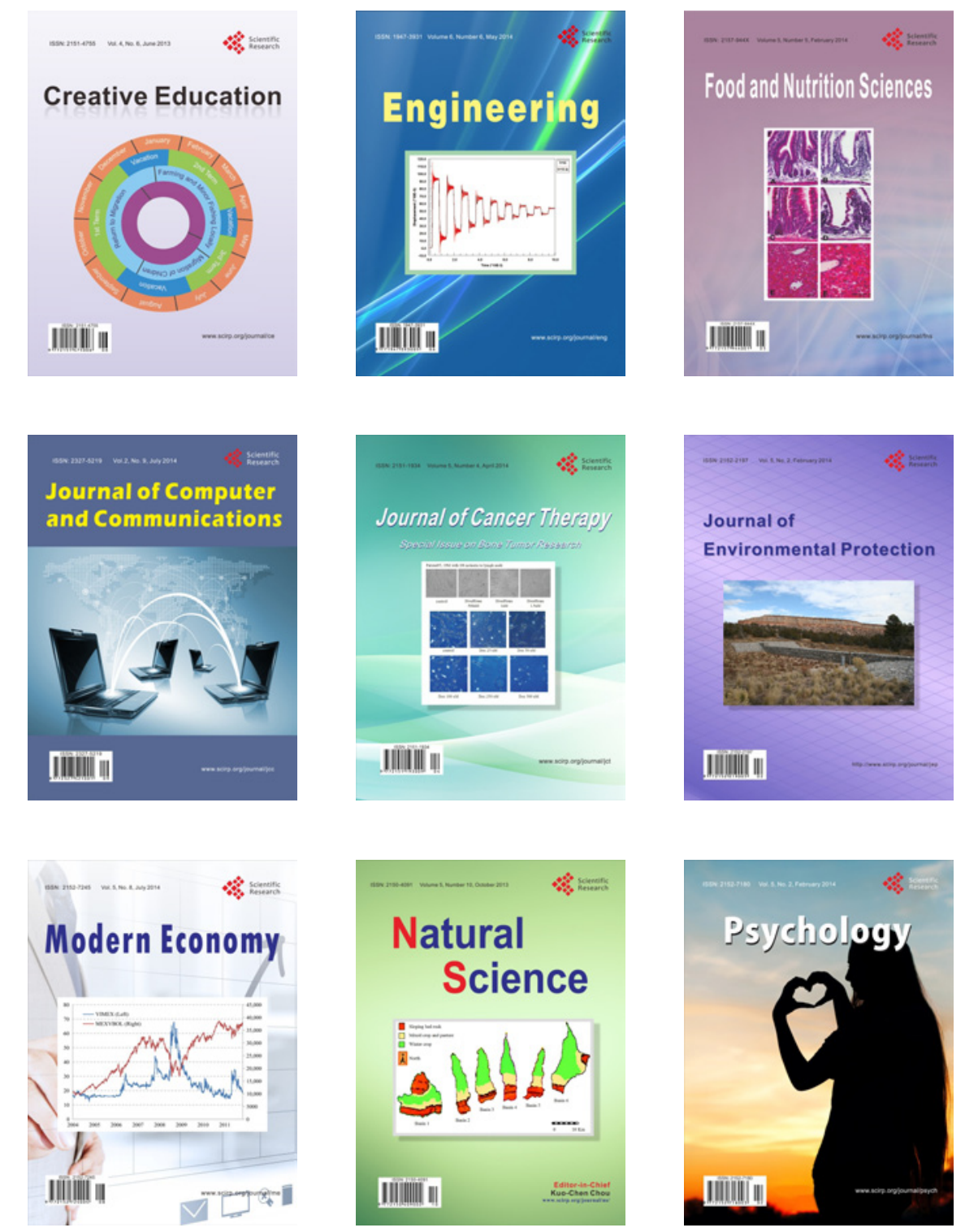